\title{
Psychological Implications of Nostalgic Scents of Childhood
}

\author{
Eirini Petratou, Nasia Paradisi, Odysseas Diamantis, Anastasios Stalikas \\ Department of Psychology Panteion, University of Social and Political Sciences, Athens, Greece \\ Email: eirini.petratou@gmail.com
}

How to cite this paper: Petratou, E., Paradisi, N., Diamantis, O., \& Stalikas, A. (2020). Psychological Implications of Nostalgic Scents of Childhood. Psychology, 11, 2066-2080. https://doi.org/10.4236/psych.2020.1112129

Received: November 27, 2020

Accepted: December 28, 2020

Published: December 31, 2020

Copyright $\odot 2020$ by author(s) and Scientific Research Publishing Inc. This work is licensed under the Creative Commons Attribution International License (CC BY 4.0).

http://creativecommons.org/licenses/by/4.0/

\begin{abstract}
There is wide-ranging literature on the emotional effects of odors but, so far, little focus on scents that evoke nostalgia and their psychological functions. This study examines the effects of nostalgia-induced scents, more specifically what are the psychological implications of scents from childhood that evoke nostalgia. The test participants sampled five childhood scents, rating each scent as to the extent to which they were familiar and elicited nostalgia and positive emotions. The study found that one of the tested childhood scents, bubblegum, was considered the most familiar but also the most nostalgic, eliciting higher self-esteem, social connection, optimism, and inspiration. Our research findings on olfaction contribute to the existing small body of experimental research on olfactory nostalgia and facilitate the understanding of the psychological implications, triggers and affective response linked with nostalgia-induced scents.
\end{abstract}

\section{Keywords}

Positive Psychology, Nostalgia, Childhood Scents, Senses, Positive Emotions

"Most of our childhood is stored not in photos, but in certain biscuits, lights of day, smells, textures of carpet." Alain de Botton, Twitter (2014)

\section{Introduction}

Scents are powerful triggers of a vast array of emotions and feelings and can evoke particular memories such as childhood memories. As a matter of fact, there are scents that are strongly linked with autobiographical childhood memories and these odor-evoked memories are highly emotional (Laird, 1935; Hurz \& Cupchik, 1992; Herz et al., 2004). Several studies in the lab have demonstrated that scent-evoked memories are more emotional than memories triggered by 
other sensory modalities (i.e. vision, verbal etc.; Herz and Cupchik, 1995; Herz, 1996, 1998b; Herz et al., 2004; Chu \& Downes, 2002). These emotional experiences serve basic psychological functions (Chrea, Delplanque, Grandjean, Cayeux, Le Calvé, Margot, Velazco, Sander, \& Scherer, 2007) and can vary depending on the qualitative features of each scent (Chrea et al., 2007). For example, research has shown that sweet odors elicit happiness and wellbeing and heavy odors provoke disgust and irritation (Chrea et al., 2007).

The so-called Proust phenomenon or Proust memory is a folk wisdom evidence that smells are powerful autobiographical memory cues (Chu \& Downes, 2002 , 2000). Research has revealed that not only do smells have this power to unlock memories, but they can also trigger older memories than memories cued by other sensory modalities such as words and pictures (Willander \& Larsson, 2006). For example, the study showed that most odor-cued memories were linked with the first decade of life ( $<10$ years), whereas memories associated with verbal and visual cues peaked in early adulthood (11 - 20 years) (Willander \& Larsson, 2006). Research exploring the strong bond between olfaction, memory and emotions has indicated that a key reason behind the unique ability of odors to vividly trigger the evocation of emotional experiences is the anatomic and functional relation between olfaction and emotion (Soudry, Lemogne, Malinvaud, Consoli, \& Bonfils, 2011). Olfactory cues activate the amygdala, while scent-cued memories are associated with greater limbic and temporal lobe activity, which is involved in positive memory processing (Royet, Zald, Versace, Costes, Lavenne, Koenig, \& Gervais, 2000).

The current study focuses on nostalgia, specifically, scent-evoked nostalgia and its psychological functions. Nostalgia is considered a bitter-sweet emotion and is constituted by happy feelings of positive memories of the past and negative feelings that derive mainly from strong longing for the past (Sedikides, Wildschut, Arndt, \& Routledge, 2006, 2008). Nostalgia is strongly linked with olfactory experiences and memories (Reid, Green, Wildschut, \& Sedikides, 2015). Research has shown that odors that evoke nostalgia have a positive impact on self-esteem, self-continuity, optimism, social connectedness, and life meaning (Reid et al., 2015).

Most research in nostalgia has been done by inducing nostalgia through narrative tasks, song lyrics and music (Reid et al., 2015). In these cases, nostalgia has been induced through reflection of nostalgic memories (Routledge, Arndt, Sedikides, \& Wildschut, 2008), through reading the lyrics of a song that was previously identified as personally nostalgic (Cheung, Wildschut, Sedikides, Hepper, Arndt, \& Vingerhoets, 2013) or through listening to a variety of brief musical excerpts (Barrett, Grimm, Robins, Wildschut, Sedikides, \& Janata, 2010).

Scent-induced nostalgia has received very few attention. A fundamental study linking scents with nostalgia was conducted with participants from several countries with the aim to develop an Emotion and Odor Scales (EOSs) instrument that will allow the measurement of affective feelings in response to several 
odors ranging from pleasant to unpleasant (Ferdenzi, Delplanque, Barbosa, Court, Guinard, Guo, Carig, Schirmer, Porcherot, Cayeux, Sander, \& Grandjean, 2013). Another example is a study conducted to investigate the psychological implications of nostalgia evoked by scents (Reid, Green, Wildschut, \& Sedikides, 2015). The study findings showed that participants higher in nostalgia proneness reported more scent-evoked nostalgia and scents that elicited higher nostalgia were more arousing, familiar and autobiographically relevant. Also, scent-evoked nostalgia predicted higher levels of positive affect, self-esteem, self-continuity, optimism, social connectedness and meaning in life (Reid et al., 2015).

\section{Present Study}

The purpose of the present study is to explore olfactory nostalgia and its psychological functions. Specifically, the aim is to test nostalgic scents from childhood and explore their psychological implications to young adults. The hypothesis is that the scent(s) that evoke(s) the highest nostalgia will evoke higher levels of 1) olfactory memory, 2) optimism, 3) self-esteem, 4) social connection, 5) life meaning and 6) inspiration. The research questions of this study are as follows:

1) Is there a childhood scent that triggers the highest nostalgia? Research shows that certain scents evoke higher nostalgia (Reid et al., 2015; Chrea et al., 2007).

2) What are the psychological implications of scents from childhood that evoke nostalgia? Research reveals that scents from childhood can have psychological implications (Reid et al., 2015; Chrea et al., 2007).

3) Is scent-evoked nostalgia correlated with a) olfactory memory, b) optimism, c) self-esteem, d) social connection, e) life meaning and f) inspiration? (Reid et al., 2015; Chrea et al., 2007).

\section{Method}

\subsection{Participants, Material and Procedure}

Participants: Initially, we recruited undergraduate students from psychology within the age range of $18-25$ years ( $\mathrm{N}=139 ; 114$ women, 24 men; $\left.M_{\text {age }}=21\right)$; they were instructed to answer to the Greek version of the Southampton Nostalgia Proneness (SNS) questionnaire (Petratou, Pezirkianidis, \& Stalikas, 2019) a month approximately prior to the olfactory test. The objective at this stage was to select the participants that would demonstrate moderate levels of nostalgia proneness (acceptable middle range of the $1-7$ SNS scale: $\approx 4$ ) to participate in the odor test. Upon completion of the first phase, we finally selected participants of moderate nostalgia proneness and age range of $18-25$ years $(\mathrm{N}=72 ; 62$ women, $10 \mathrm{men} ; M_{\text {age }}=21$ ).

Material: 5 scents in the form of scented oils (chocolate, bubblegum, cotton candy, popcorn, butter caramel) corresponding to childhood were selected cov- 
ering a basic range of the sweets and treats category. These scents were chosen in order to have a congruent category of scents (sweets and treats) that have references to childhood-so they could evoke nostalgia—without being affected by factors such as place of origin [e.g. nostalgia that could be caused by the smell of flowers or fruits could be related to the frequency of exposure to them (i.e. countryside vs city) or to specific periods of time (i.e. summer holidays vs winter) or seasons (i.e. Christmas)]. The scented oils were presented in glass test tubes, masked so that the participants couldn't recognize the scent from any visual cue. The scented oils were obtained from a company (Nature's Garden Wholesale Candle and Soap Supplies) that sells and fragrances in 1/2-ounce vials and has been used for similar studies (Reid et al., 2015). For each scent, participants indicated completed scent-level measures (adapted from Barrett et al., 2010; Reid et al., 2015) (see also Measures 3.2).

Procedure: Participants were instructed two or three days prior to the test to avoid consuming food neither earlier nor later than 2 hours before the beginning of the day of the test since the olfactory perception could be affected by the degree of hunger (Ramaekers, Boesveldt, Lakemond, van Boekel, \& Luning, 2014); they were also instructed to not wear any perfume on the day of the test to avoid any bias or fatigue during when sniffing the test odors (the same guideline was applied for the test moderator).

The test took place in a controlled lab setting with no visual or olfactory stimuli that could distract participants during the experimental process; the room was also ventilated with fresh air in between sessions to maintain a neutral and unbiased setting for each olfactory session. Participants were placed at two meters between each other to avoid any interaction or bias in the evaluation. Initially, each participant was asked to take a deep breath and relax by closing his/her eyes for 10 seconds. The goal was to establish a common baseline/starting point for all participants before the beginning of the experimental measurements. Then, the test material was distributed to the participants and the measurements took place. Each participant sniffed five different scents in a sequential order; randomization was applied to avoid any order effect. The smell of each scent lasted 3 - 4 seconds while the inter-test interval between the smell of the scents was 2.5 minutes-an average duration indicated by the relevant literature regarding the inter-test interval required during the smell of different scents-during this time the participants were asked to "clean" the olfactory tract by inhaling air molecules (Ramaekers et al., 2014).

\subsection{Measures}

\subsubsection{Southampton Nostalgia Scale (SNS)-Translated in Greek}

The SNS gives participants a definition of "nostalgia" as provided by the Oxford Dictionary-a sentimental longing for the past-and then asks them to rate nostalgia proneness by filling seven items in total; four items measure frequency of nostalgic engagement ("how often do you experience nostalgia, "generally speaking, how often do you bring to mind nostalgic experiences", specifically, 
how often do you bring to mind nostalgic experiences"; 1 = very rarely, 7 = very frequently) and three items assessing the importance assigned to nostalgic engagement ("how valuable is nostalgia for you", "how important is it for you to bring to mind nostalgic experiences?", "how significant is for you to feel nostalgic", "how prone are you to feeling nostalgic"; $1=$ not at all, $7=$ very much). For the test, we used the Greek version of the SNS scale (Petratou et al., 2019).

\subsubsection{Odor-Induced Nostalgia Assessment Questionnaire}

The questionnaire assesses whether each scent caused nostalgia on a 7-point scale (i.e.-How much nostalgia do you feel when you smell the scent? "I feel somewhat nostalgic", "I feel nostalgia"). The three questions were calculated after the end of the measurements in order to form a single indicator of olfactory memory for each scent (Reid et al., 2015; Barrett et al., 2010).

\subsubsection{Olfactory Memory Assessment Questionnaire}

The questionnaire assesses the degree of olfactory memory. Questions that measure on a 7-point scale the following were used: olfactory recognition (i.e. "I recognize what the scent is"), olfactory identification (i.e. "Can I identify the scent”), olfactory familiarity (i.e. “The scent is familiar) (Reid et al., 2015; Barrett et al., 2010). The questions were calculated after the end of the measurements in order to form a single indicator of olfactory memory for each scent (Herz \& Engen, 1996).

\subsubsection{Psychological Processes of Nostalgia Questionnaire}

Questionnaire that measures the degree of positive effect of nostalgia on the positive variables (Reid et al., 2015; Cheung et al., 2013) of the olfactory experience of the scent (Reid et al., 2015). It included questions about the degree to which each individual experiences for each scent (7-point scale) self-esteem [(a) perfume makes me feel good about myself, (b) perfume makes me feel worthwhile (Reid et al., 2015; Barrett et al., 2010)], optimism [(a) perfume makes me feel optimistic about the future, (b) perfume makes me want to take on new challenges (Reid et al., 2015; Barrett et al., 2010)], social connectedness [(a) perfume makes me feel connected to loved ones, (b) perfume makes me feel loved (Reid et. al., 2015; Barrett et al., 2010)], meaning of life [(a) perfume makes me feel that life has meaning, (b) perfume makes me feel that life has a purpose (Reid et al., 2015; Barrett et al., 2010)], inspiration [(a) perfume inspires me, (b) perfume makes me want to create].

\section{Results}

The statistical analysis was carried out with the use of SPSS Vol. 25.

Reliability analysis. Cronbach's Alpha-coefficient of reliability-was calculated to explore internal consistency of the scales that were used to measure how closely related the set of items per dimension they are as a group (Cohen, Cohen, 
West, \& Aiken, 2002).

Normality testing. Shapiro-Wilk test was used to test if the scores in the sample are normally distributed. The test is based on the correlation between the data and the corresponding normal scores and is recommended by researchers as the best choice for testing the normality of data (Thode, 2002).

Kruskal- Wallis test (or one-way ANOVA on ranks). To test if there are significant differences across the scents used for the study we used Kruskal-Wallis test, a non-parametric method. It is used for comparing two or more independent samples of equal or different sample sizes. The parametric equivalent of the Kruskal-Wallis test is the one-way analysis of variance (ANOVA). A significant Kruskal-Wallis test indicates that at least one sample stochastically dominates one other sample. For analyzing the specific sample pairs for stochastic dominance, Dunn's test, with Bonferroni correction, was used (Corder \& Foreman, 2009).

Correlation analysis. Correlation analysis was conducted to explore relationship-correlation coefficients ( $\mathrm{r}$ - - between the scent-level measures. Strong positive correlations are considered the ones with $r>0.7$ (Akoglu, 2018).

\subsection{Reliability Analysis}

Reliability analysis shows that all scent-level measures have a high level of internal consistency. Reliability coefficients (Cronbach's Alpha) per dimension are as follows: Nostalgia, $\alpha=0.972$, Self-esteem, $\alpha=0.894$, Optimism, $\alpha=0.878$, Social connection, $\alpha=0.856$, Life meaning, $\alpha=0.937$, Inspiration, $\alpha=0.945$, Olfactory memory, $\alpha=0.923$.

\subsection{Normality Testing}

A Shapiro-Wilk test showed a significant departure from normality for most scents for dimensions tested: the sig. value of the Shapiro-Wilk Test is below than 0.05 . Sig. below 0.05 , means that the data significantly deviate from a normal distribution (see Table 1 below).

\subsection{Kruskal-Wallis Test}

A Kruskal-Wallis $\mathrm{H}$ test showed that there was a statistically significant difference in nostalgia, $\chi^{2}(2)=23.205, p=0.000$, self-esteem, $\chi^{2}(2)=11.116, p=0.025$, optimism, $\chi^{2}(2)=11.857, p=0.018$, social connection, $\chi^{2}(2)=11.836, p=0.019$, inspiration, $\chi^{2}(2)=10.317, p=0.035$ and olfactory memory, $\chi^{2}(2)=47.353, p=$ 0.000 , scores between the different scents; no statistical difference is observed in life meaning, $\chi^{2}(2)=2.428, p=0.658$ (see Table 2 ).

The mean rank of nostalgia score was 152.14 for Butter caramel, 186.35 for Cotton candy, 162.33 for Chocolate, 227.92 for Bubblegum and 173.76 for Pop Corn. For self-esteem score, the mean rank was 160.48 for Butter caramel, 195.13 for Cotton candy, 168.31 for Chocolate, 208.50 for Bubblegum and 170.09 for Pop Corn. For optimism, it was 164.66 for Butter caramel, 191.19 for Cotton 
Table 1. Shapiro-Wilk test ${ }^{\mathrm{a}}$.

\begin{tabular}{|c|c|c|c|c|}
\hline & Odor & Shapiro-Wilk Statistic ${ }^{*}$ & df & Sig. \\
\hline \multirow[t]{5}{*}{ Nostalgia } & Butter caramel & 0.904 & 71 & 0 \\
\hline & Cotton Candy & 0.964 & 72 & 0.037 \\
\hline & Chocolate & 0.944 & 71 & 0.003 \\
\hline & Bubblegum & 0.925 & 72 & 0 \\
\hline & Pop Corn & 0.921 & 68 & 0 \\
\hline \multirow[t]{5}{*}{ Self-esteem } & Butter caramel & 0.918 & 71 & 0 \\
\hline & Cotton Candy & 0.982 & 72 & 0.392 \\
\hline & Chocolate & 0.935 & 71 & 0.001 \\
\hline & Bubblegum & 0.964 & 72 & 0.035 \\
\hline & Pop Corn & 0.934 & 68 & 0.001 \\
\hline \multirow[t]{5}{*}{ Optimism } & Butter caramel & 0.931 & 71 & 0.001 \\
\hline & Cotton Candy & 0.98 & 72 & 0.301 \\
\hline & Chocolate & 0.916 & 71 & 0 \\
\hline & Bubblegum & 0.953 & 72 & 0.009 \\
\hline & Pop Corn & 0.919 & 68 & 0 \\
\hline \multirow[t]{5}{*}{ Social connection } & Butter caramel & 0.918 & 71 & 0 \\
\hline & Cotton Candy & 0.958 & 72 & 0.017 \\
\hline & Chocolate & 0.931 & 71 & 0.001 \\
\hline & Bubblegum & 0.94 & 72 & 0.002 \\
\hline & Pop Corn & 0.911 & 68 & 0 \\
\hline \multirow[t]{5}{*}{ Life meaning } & Butter caramel & 0.909 & 71 & 0 \\
\hline & Cotton Candy & 0.973 & 72 & 0.13 \\
\hline & Chocolate & 0.924 & 71 & 0 \\
\hline & Bubblegum & 0.935 & 72 & 0.001 \\
\hline & Pop Corn & 0.936 & 68 & 0.002 \\
\hline \multirow[t]{5}{*}{ Inspiration } & Butter caramel & 0.899 & 71 & 0 \\
\hline & Cotton Candy & 0.96 & 72 & 0.023 \\
\hline & Chocolate & 0.902 & 71 & 0 \\
\hline & Bubblegum & 0.935 & 72 & 0.001 \\
\hline & Pop Corn & 0.923 & 68 & 0 \\
\hline \multirow[t]{5}{*}{ Olfactory Memory } & Butter caramel & 0.948 & 71 & 0.006 \\
\hline & Cotton Candy & 0.968 & 72 & 0.066 \\
\hline & Chocolate & 0.919 & 71 & 0 \\
\hline & Bubblegum & 0.82 & 72 & 0 \\
\hline & Pop Corn & 0.93 & 68 & 0.001 \\
\hline
\end{tabular}

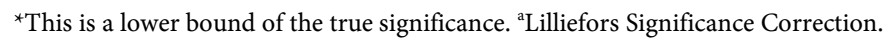


Table 2. Kruskal-Wallis test.

\begin{tabular}{cccccccc}
\hline \multicolumn{7}{c}{ Test Statistics, } \\
\hline & Nostalgia & Self-esteem & Optimism & Social-connection & Life-meaning & Inspiration & Olfactory-Memory \\
\hline Kruskal-Wallis H & 23.205 & 11.116 & 11.857 & 11.836 & 2.428 & 10.317 & 47.353 \\
df & 4 & 4 & 4 & 4 & 4 & 4 & 4 \\
Asymp. Sig. & 0.000 & 0.025 & 0.018 & 0.019 & 0.658 & 0.035 & 0.000 \\
\hline
\end{tabular}

${ }^{\mathrm{a} K r u s k a l}$ Wallis Test; ${ }^{\mathrm{b}}$ Grouping Variable: Odor.

candy, 165.01 for Chocolate 209.93 for Bubblegum and 163.59 for Pop Corn. For social connection, it was 157.61 for Butter caramel, 197.53 for Cotton candy, 164.49 for Chocolate, 206.00 for Bubblegum and 174.28 for Pop Corn. For life meaning, the score was 167.19 for Butter caramel, 186.50 for Cotton candy, 179.83 for Chocolate, 190.42 for Bubblegum and 173.39 for Pop Corn. For inspiration, it was 163.81 for Butter caramel, 190.19 for Cotton candy, 166.46 for Chocolate, 210.31 for Bubblegum and 171.74 for Pop Corn. For olfactory memory, the score was 148.59 for Butter caramel, 162.94 for Cotton candy, 167.05 for Chocolate, 254.31 for Bubblegum and 169.60 for Pop Corn (see Table 3).

\subsection{Dunn's Multiple Comparison Test}

A Kruskal-Wallis test provided very strong evidence of a difference $(p<0.001)$ between the mean ranks of at least one pair of groups. Dunn's pairwise tests were carried out for the five pairs of groups. There was very strong evidence ( $p<$ 0.001 , adjusted using the Bonferroni correction) of a difference between Bubblegum and Cotton Candy along with Bubblegum and Butter Caramel in olfactory memory; the median of olfactory memory for Bubblegum was 254.31, 162.94 for Cotton candy and 148.59 for Butter caramel (see also Table 3). Also, significant differences $(p<0.001)$ were observed in nostalgia between Bubblegum and Butter caramel, Bubblegum and Chocolate, Bubblegum and Pop Corn; the median of nostalgia for Bubblegum was 173.76, 152.14 for Butter caramel, 162.33 for Chocolate and 173.76 for Pop Corn (see also Table 3). There was no evidence of a difference between the other pairs (Field, 2013) (see Figures 1-7).

\subsection{Correlation Analysis (Pearson Correlation)}

A Spearman's rank-order correlation was run to determine the relationship between nostalgia and self-esteem, optimism, social connection, life meaning, inspiration and olfactory memory marks. There was a strong, positive and statistically significant correlation between nostalgia and self-esteem $\left(r_{s}(8)=0.722\right)$, nostalgia and optimism $\left(r_{s}(8)=0.667\right)$, nostalgia and social connection $\left(r_{s}(8)=\right.$ $0.754)$ and nostalgia and inspiration $\left(r_{s}(8)=0.698\right)$. Moderate, positive and statistically significant correlation between nostalgia and life meaning $\left(r_{s}(8)=\right.$ 0.637 ) and nostalgia and olfactory memory $\left(r_{s}(8)=0.586\right.$ ) (Akoglu, 2018) (see Table 4). 
Table 3. Mean ranks.

\begin{tabular}{|c|c|c|c|}
\hline \multicolumn{4}{|c|}{ Ranks } \\
\hline & Odor & $\mathbf{N}$ & Mean Rank \\
\hline \multirow[t]{6}{*}{ Nostalgia } & Butter caramel & 72 & 152.14 \\
\hline & Cotton Candy & 72 & 186.35 \\
\hline & Chocolate & 72 & 162.33 \\
\hline & Bubblegum & 72 & 227.92 \\
\hline & Pop Corn & 72 & 173.76 \\
\hline & Total & 360 & \\
\hline \multirow[t]{6}{*}{ Self-esteem } & Butter caramel & 72 & 160.48 \\
\hline & Cotton Candy & 72 & 195.13 \\
\hline & Chocolate & 72 & 168.31 \\
\hline & Bubblegum & 72 & 208.50 \\
\hline & Pop Corn & 72 & 170.09 \\
\hline & Total & 360 & \\
\hline \multirow[t]{6}{*}{ Optimism } & Butter caramel & 71 & 164.66 \\
\hline & Cotton Candy & 72 & 191.19 \\
\hline & Chocolate & 71 & 165.01 \\
\hline & Bubblegum & 72 & 209.93 \\
\hline & Pop Corn & 71 & 163.59 \\
\hline & Total & 357 & \\
\hline \multirow[t]{6}{*}{ Social-connection } & Butter caramel & 72 & 157.61 \\
\hline & Cotton Candy & 72 & 197.53 \\
\hline & Chocolate & 72 & 164.49 \\
\hline & Bubblegum & 72 & 206.00 \\
\hline & Pop Corn & 71 & 174.28 \\
\hline & Total & 359 & \\
\hline \multirow[t]{6}{*}{ Life-meaning } & Butter caramel & 72 & 167.19 \\
\hline & Cotton Candy & 72 & 186.50 \\
\hline & Chocolate & 72 & 179.83 \\
\hline & Bubblegum & 72 & 190.42 \\
\hline & Pop Corn & 70 & 173.39 \\
\hline & Total & 358 & \\
\hline \multirow[t]{6}{*}{ Inspiration } & Butter caramel & 72 & 163.81 \\
\hline & Cotton Candy & 72 & 190.19 \\
\hline & Chocolate & 72 & 166.46 \\
\hline & Bubblegum & 72 & 210.31 \\
\hline & Pop Corn & 72 & 171.74 \\
\hline & Total & 360 & \\
\hline \multirow[t]{2}{*}{ Olfactory-Memory } & Butter caramel & 72 & 148.59 \\
\hline & Cotton Candy & 72 & 162.94 \\
\hline
\end{tabular}




\section{Continued}

\begin{tabular}{lcc}
\hline Chocolate & 72 & 167.05 \\
Bubblegum & 72 & 254.31 \\
Pop Corn & 72 & 169.60 \\
Total & 360 & \\
\hline
\end{tabular}

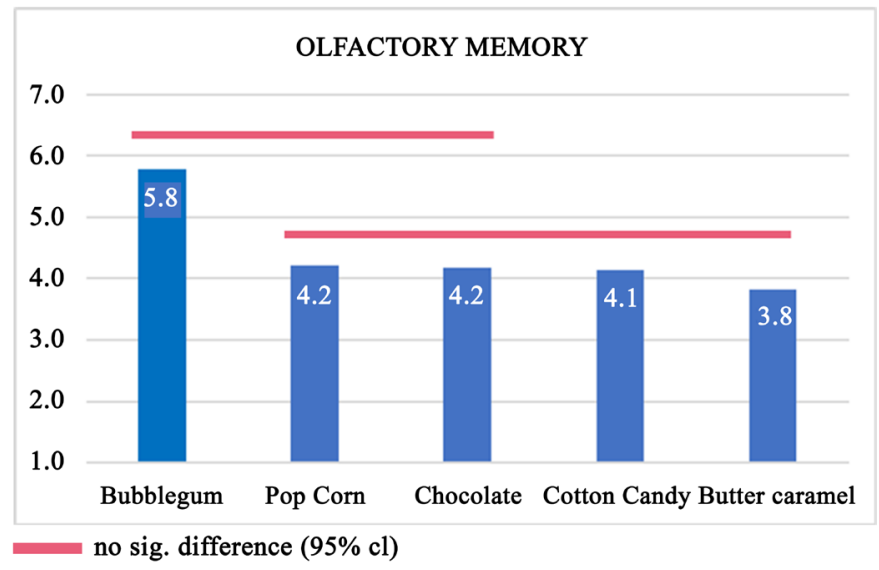

Figure 1. Olfactory memory.

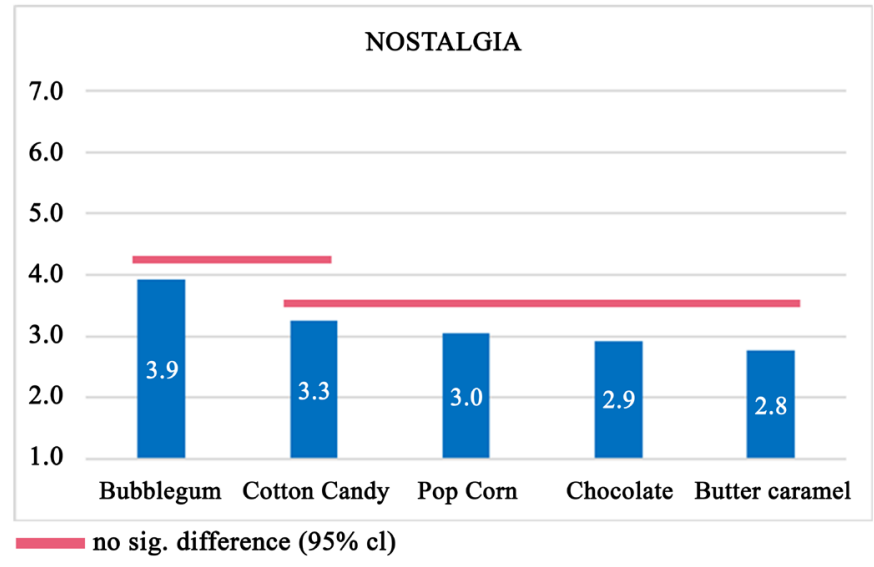

Figure 2. Nostalgia.

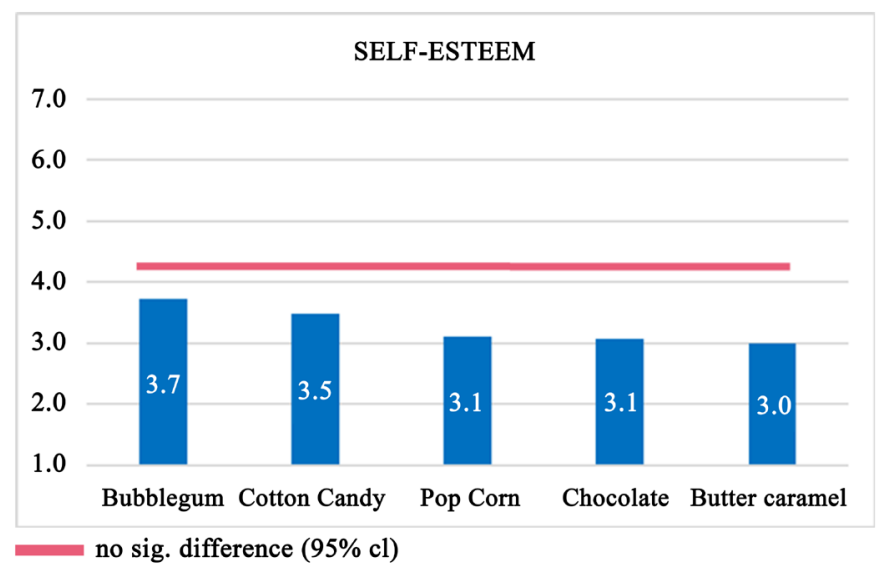

Figure 3. Self-esteem. 


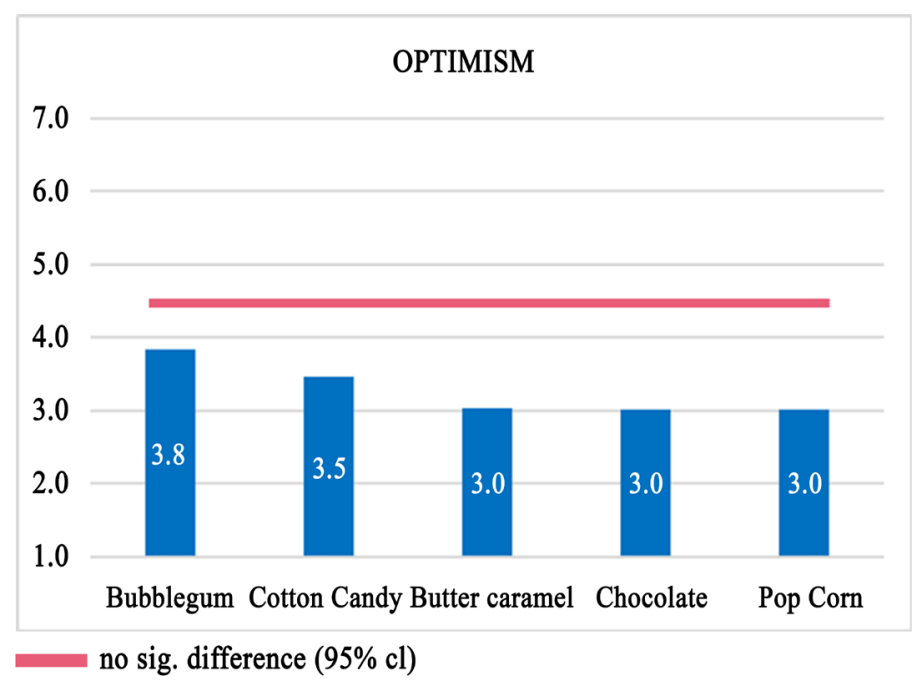

Figure 4. Optimism.

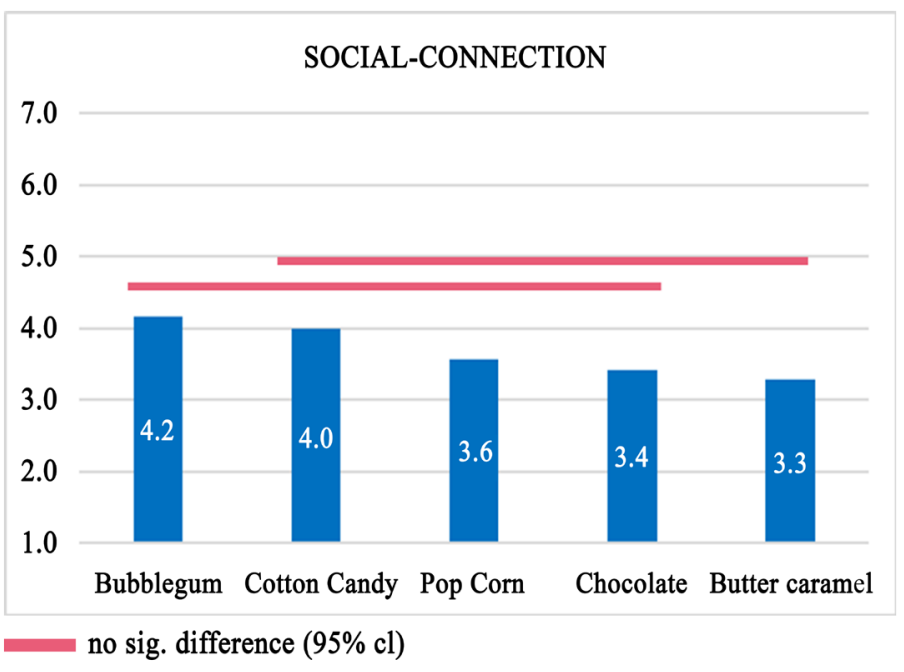

Figure 5. Social connection.

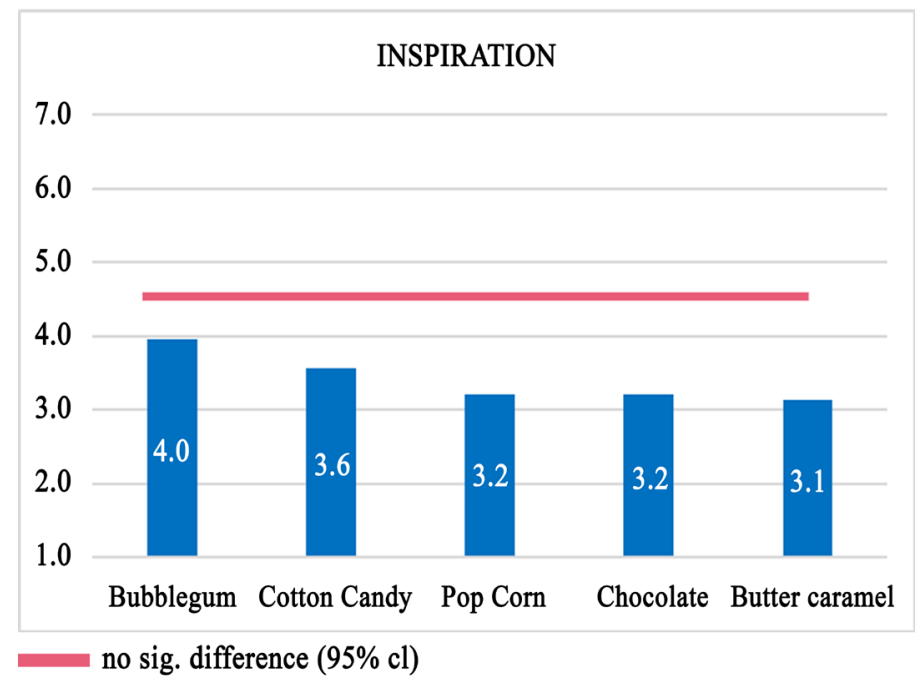

Figure 6. Inspiration. 


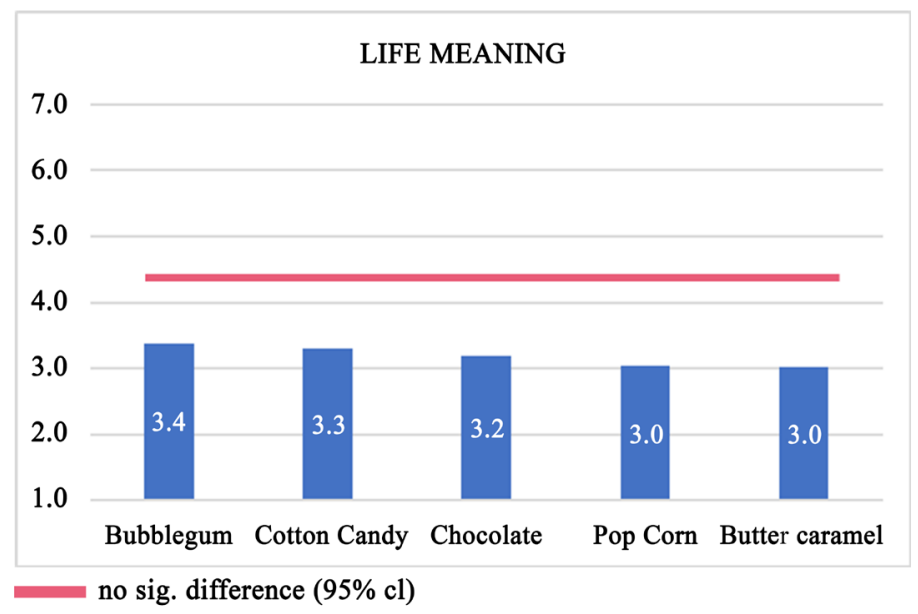

Figure 7. Life meaning.

Table 4. Pearson correlation.

\begin{tabular}{|c|c|c|c|c|c|c|c|c|}
\hline & & Nostalgia & $\begin{array}{c}\text { Self } \\
\text { esteem }\end{array}$ & Optimism & $\begin{array}{c}\text { Social } \\
\text { connection }\end{array}$ & $\begin{array}{c}\text { Life } \\
\text { meaning }\end{array}$ & Inspiration & $\begin{array}{l}\text { Olfactory } \\
\text { Memory }\end{array}$ \\
\hline \multirow[t]{3}{*}{ Nostalgia } & Correlation Coefficient & 1 & $0.722^{* *}$ & $0.667^{* *}$ & $0.754^{* *}$ & $0.637^{* *}$ & $0.698^{* *}$ & $0.586^{* *}$ \\
\hline & Sig. (2-tailed) & & 0 & 0 & 0 & 0 & 0 & 0 \\
\hline & $\mathrm{N}$ & 360 & 360 & 357 & 359 & 358 & 360 & 360 \\
\hline \multirow[t]{3}{*}{ Self-esteem } & Correlation Coefficient & $0.722^{* *}$ & 1 & $0.853^{* *}$ & $0.794^{* *}$ & $0.786^{* *}$ & $0.806^{* *}$ & $0.507^{\star *}$ \\
\hline & Sig. (2-tailed) & 0 & & 0 & 0 & 0 & 0 & 0 \\
\hline & $\mathrm{N}$ & 360 & 360 & 357 & 359 & 358 & 360 & 360 \\
\hline \multirow[t]{3}{*}{ Optimism } & Correlation Coefficient & $0.667^{* *}$ & $0.853^{* *}$ & 1 & $0.748^{* *}$ & $0.796^{* *}$ & $0.802^{* *}$ & $0.469^{* *}$ \\
\hline & Sig. (2-tailed) & 0 & 0 & & 0 & 0 & 0 & 0 \\
\hline & $\mathrm{N}$ & 357 & 357 & 357 & 356 & 355 & 357 & 357 \\
\hline \multirow[t]{3}{*}{ Social connection } & Correlation Coefficient & $0.754^{* *}$ & $0.794^{* *}$ & $0.748^{* *}$ & 1 & $0.729^{* *}$ & $0.801^{\star *}$ & $0.603^{* *}$ \\
\hline & Sig. (2-tailed) & 0 & 0 & 0 & & 0 & 0 & 0 \\
\hline & $\mathrm{N}$ & 359 & 359 & 356 & 359 & 357 & 359 & 359 \\
\hline \multirow[t]{3}{*}{ Life meaning } & Correlation Coefficient & $0.637^{* *}$ & $0.786^{* *}$ & $0.796^{* *}$ & $0.729^{* *}$ & 1 & $0.761^{\star *}$ & $0.390^{* *}$ \\
\hline & Sig. (2-tailed) & 0 & 0 & 0 & 0 & & 0 & 0 \\
\hline & $\mathrm{N}$ & 358 & 358 & 355 & 357 & 358 & 358 & 358 \\
\hline \multirow[t]{3}{*}{ Inspiration } & Correlation Coefficient & $0.698^{* *}$ & $0.806^{* *}$ & $0.802^{* *}$ & $0.801^{* *}$ & $0.761^{* *}$ & 1 & $0.523^{* *}$ \\
\hline & Sig. (2-tailed) & 0 & 0 & 0 & 0 & 0 & & 0 \\
\hline & $\mathrm{N}$ & 360 & 360 & 357 & 359 & 358 & 360 & 360 \\
\hline \multirow[t]{3}{*}{ Olfactory Memory } & Correlation Coefficient & $0.586^{\star *}$ & $0.507^{\star *}$ & $0.469^{* *}$ & $0.603^{* *}$ & $0.390^{* *}$ & $0.523^{* *}$ & 1 \\
\hline & Sig. (2-tailed) & 0 & 0 & 0 & 0 & 0 & 0 & \\
\hline & $\mathrm{N}$ & 360 & 360 & 357 & 359 & 358 & 360 & 360 \\
\hline
\end{tabular}

${ }^{* *}$ Correlation is significant at the 0.01 level (2-tailed). 


\section{Discussion}

The results of the study provide empirical support for the fact that childhood scents can trigger nostalgia and that there are scents that evoke significantly higher nostalgia than others-bubblegum, cotton candy (see Figure 2). Also, the analysis revealed that the scent that elicited the highest nostalgia, bubblegum, (see Figure 2) triggered the highest olfactory memory (see Figure 1) showing the strong linkage between nostalgia and memory activation through olfaction (Chrea et al., 2007).

Furthermore, the study confirms the psychological functions and particularly the positive impact of scent-evoked nostalgia (Chrea et al., 2007). Specifically, the study shows strong, positive correlation between nostalgia and self-esteem, optimism, social connection and inspiration (see Table 4) (Reid, Green, Wildschut, \& Sedikides, 2015).

\subsection{Limitations and Future Directions}

The results of this study should be considered directional since there are various factors that should be taken into consideration for future research. For example, the vast majority of the sample was women $\left(M_{\text {age }}=21\right)$.

Another important factor to consider is the category of scents that were used. It would be interesting to explore psychological functions of a broader variety of scent categories and investigate if there are differences in their psychological implications factoring in gender, age or other individual differences (i.e. personality traits).

\subsection{Implications}

Overall, the study could have several scientific and clinical applications. For example, mental health professionals could use childhood scents that trigger nostalgia in their interventions with clients-during the therapeutic process-to access difficult memories for trauma processing or for certain exercises of calming down (Torre, 2008).

\section{Conflicts of Interest}

The authors declare no conflicts of interest regarding the publication of this paper.

\section{References}

Akoglu, H. (2018). User's Guide to Correlation Coefficients. Turkish Journal of Emergency Medicine, 18, 91-93. https://doi.org/10.1016/j.tjem.2018.08.001

Barrett, F. S., Grimm, K. J., Robins, R. W., Wildschut, T., Sedikides, C., \& Janata, P. (2010). Music-Evoked Nostalgia: Affect, Memory, and Personality. Emotion, 10, 390-403. https://doi.org/10.1037/a0019006

Cheung, W. Y., Wildschut, T., Sedikides, C., Hepper, E. G., Arndt, J., \& Vingerhoets, A. J. J. M. (2013). Back to the Future: Nostalgia Increases Optimism. Personality and Social Psychology Bulletin, 39, 1484-1496. https://doi.org/10.1177/0146167213499187 
Chrea, C., Delplanque, S., Grandjean, D., Cayeux, I., Le Calvé, B., Margot, C., Velazco, M. I., Sander, D., \& Scherer, R. K. (2007). The Emotional Power of Odors: Identifying the Dimensions Referring to Feelings Produced by Odors. SPISE 2007: Proceedings, Ho Chi Minh City, 26-27 July 2007, 43-49. https://doi.org/10.1093/chemse/bjn052

Chu, S., \& Downes, J. J. (2000). Odor-Evoked Autobiographical Memories: Psychological Investigations of Proustian Phenomena. Chemical Senses, 25, 111-116. https://doi.org/10.1093/chemse/25.1.111

Chu, S., \& Downes, J. J. (2002). Proust Nose Best: Odors Are Better Cues of Autobiographical Memory. Memory and Cognition, 30, 511-518. https://doi.org/10.3758/BF03194952

Cohen, J., Cohen, P., West, S. G., \& Aiken, L. S. (2002). Applied Multiple Regression/Correlation Analysis for the Behavioral Sciences (2nd ed.). Hillsdale, NJ: Lawrence Erlbaum Associates Publishers.

Corder, G. W., \& Foreman, D. I. (2009). Nonparametric Statistics for Non-Statisticians. Hoboken, NJ: John Wiley \& Sons. https://doi.org/10.1002/9781118165881

Ferdenzi, C., Delplanque, S., Barbosa, P., Court, K., Guinard, J., Guo, T., Carig, Schirmer, S. R., Porcherot, C., Cayeux, I., Sander, D., \& Grandjean, D. (2013). Affective Semantic Space of Scents. Towards a Universal Scale to Measure Self-Reported Odor-Related Feelings. Food Quality and Preferences, 30, 128-138.

https://doi.org/10.1016/j.foodqual.2013.04.010

Field, A. (2013). Discovering Statistics Using SPSS: And Sex and Drugs and Rock " $n$ " Roll (4th ed.). London: SAGE.

Herz, R. S. (1996). A Comparison of Olfactory, Visual and Tactile Cues for Emotional and Non-Emotional Associated Memories. Chemical Senses, 21, 614-615.

Herz, R. S. (1998b). An Examination of Objective and Subjective Measures of Experience Associated to Odors, Music and Paintings. Empirical Studies of the Arts, 16, 137-152. https://doi.org/10.2190/C43T-CJR2-9LPD-R0PB

Herz, R. S., \& Cupchik, G. C. (1995). The Emotional Distinctiveness of Odor-Evoked Memories. Chemical Senses, 20, 517-528. https://doi.org/10.1093/chemse/20.5.517

Herz, R. S., \& Engen, T. (1996). Odor Memory: Review and Analysis. Psychonomic Bulletin \& Review, 3, 300-313. https://link.springer.com/article/10.3758/BF03210754 https://doi.org/10.3758/BF03210754

Herz, R. S., Schankler, C., \& Beland, S. (2004). Olfaction, Emotion and Associative Learning: Effects on Motivated Behavior. Motivation and Emotion, 28, 363-383. https://doi.org/10.1007/s11031-004-2389-x

Hurz, R. S., \& Cupchik, G. C. (1992). An Experimental Characterization of Odor Evoked Memories in Humans. Chemical Senses, 17, 519-528. https://doi.org/10.1093/chemse/17.5.519

Laird, D. A. (1935). What Can You Do with Your Nose? The Scientific Monthly, 41, 126-130.

Petratou, E., Perzikianidis, C., \& Stalikas, A. (2019). The Greek Version of the Southampton Nostalgia Scale: Psychometric Properties in Young Adults and Associations with Life Satisfaction, Positive and Negative Emotions, Time Perspective and Wellbeing. Journal of Psychological and Behavioral Sciences, 13, 1.

Ramaekers, M. G., Boesveldt, S., Lakemond, C. M. M., van Boekel, M. A. J. S., \& Luning, P. A. (2014). Odors: Appetizing or Satiating? Development of Appetite during Odor Exposure over Time. International Journal of Obesity, 38, 650-656.

https://doi.org/10.1038/ijo.2013.143 
Reid, C. A., Green, J. D., Wildschut, T., \& Sedikides, C. (2015). Scent-Evoked Nostalgia. Memory, 23, 157-166. https://doi.org/10.1080/09658211.2013.876048

Routledge, C., Arndt, J., Sedikides, C., \& Wildschut, T. (2008). A Blast from the Past: The Terror Management Function of Nostalgia. Journal of Experimental Social Psychology, 44, 132-140. https://doi.org/10.1016/j.jesp.2006.11.001

Royet, J.-P., Zald, D., Versace, R., Costes, N., Lavenne, F., Koenig, O., \& Gervais, R. (2000). Emotional Responses to Pleasant and Unpleasant Olfactory, Visual, and Auditory Stimuli: A Positron Emission Tomography Study. The Journal of Neuroscience, 20, 7752-7759. https://doi.org/10.1523/JNEUROSCI.20-20-07752.2000

Sedikides, C., Wildschut, T., Arndt, J., \& Routledge, C. (2006). Affect and the Self. In J. P. Forgas (Ed.), Affect in Social Thinking and Behavior: Frontiers in Social Psychology (pp. 197-215). New York: Psychology Press.

Sedikides, C., Wildschut, T., Arndt, J., \& Routledge, C. (2008). Nostalgia Past, Present, Future. Current Directions in Psychological Science, 17, 304-307. https://doi.org/10.1111/j.1467-8721.2008.00595.x

Soudry, Y., Lemogne, C., Malinvaud, D., Laccourreye, O., Consoli, S.-M., \& Bonfils, P. (2011). Olfactory System and Emotion: Common Substrates. European Annals of Otorhinolaryngology, Head and Neck Disease, 128, 18-23.

https://doi.org/10.1016/j.anorl.2010.09.007

Thode, H. J. (2002). Testing for Normality. New York: Marcel Dekker. https://doi.org/10.1201/9780203910894

Torre, M. A. (2008). Integrated Perspectives: Aromatherapy and the Use of Scents in Psychotherapy. Perspectives in Psychiatric Care, 39, 35-37. https://doi.org/10.1111/j.1744-6163.2003.tb00672.x

Willander, J., \& Larsson, M. (2006). Smell Your Way Back to Childhood: Autobiographical Odor Memory. Psychonomic Bulletin and Review, 13, 240-244.

https://doi.org/10.3758/BF03193837 